\title{
Forensic autopsy-confirmed COVID-19-induced out-of-hospital cardiac arrest
}

\author{
Laurent Fanton $^{1,2 \#}$, Isabelle Nahmani ${ }^{1,2 \#}$, Marie Epain ${ }^{1}$, Anne-Sophie Advenier ${ }^{1}$, Martin Cour ${ }^{2,3}$, \\ David Meyronet ${ }^{2,4}$, Laurent Argaud ${ }^{2,3}$
}

${ }^{1}$ Hospices Civils de Lyon, Edouard Herriot Hospital, Service of Legal Medicine, Lyon, France; ${ }^{2}$ Université de Lyon, Claude-Bernard Lyon 1 University, Lyon-Est Medical School, Lyon, France; ${ }^{3}$ Hospice Civils de Lyon, Edouard Herriot Hospital, Department of Medical Intensive Care, Lyon, France; ${ }^{4}$ Hospices Civils de Lyon, Eastern Hospital Group, Department of Pathology, Lyon, France

Contributions: (I) Conception and design: L Fanton, L Argaud; (II) Administrative support: L Argaud; (III) Provision of study materials or patients: L Fanton, L Argaud; (IV) Collection and assembly of data: All authors; (V) Data analysis and interpretation: All authors; (VI) Manuscript writing: All authors; (VII) Final approval of manuscript: All authors.

\#These authors contributed equally to this work.

Correspondence to: Pr. Laurent Argaud, MD, PhD. Service de Médecine Intensive-Réanimation, Hôpital Edouard Herriot, 5, Place d’Arsonval, 69437

Lyon Cedex 03, France. Email: laurent.argaud@chu-lyon.fr.

\begin{abstract}
Background: In the setting of severe acute respiratory syndrome coronavirus 2 (SARS-CoV-2) infection, data from autopsy in subjects who died at home during lockdown are scarce. We here report the first forensic autopsy series of coronavirus disease 2019 (COVID-19)-related out-of-hospital cardiac arrest (OHCA).

Methods: Between March and April 2020, four COVID-19-related OHCA were autopsied at the Institute of Legal Medicine of the metropolitan area of Lyon (France) according safe recommended procedures.

Results: Four Caucasian individuals (3 men/1 woman; age: $56.8 \pm 2.1$ years, body mass index: $29.5 \pm 7.4 \mathrm{~kg} / \mathrm{m}^{2}$ ), presenting symptomatic COVID-19 were autopsied. Autopsies of 3 individuals reported natural death by acute respiratory failure implicating SARS-CoV-2 with typical COVID-19 pulmonary aspect of gross findings and pulmonary microscopy findings, i.e., diffusely congestive edematous lungs with peripheral thrombi and diffuse alveolar damage (DAD) at different stages of inflammatory reaction. For one individual, autopsy concluded of violent death due to suicidal acute alcohol intoxication in a patient that could no longer endure COVID-19 lockdown. No significant lesions were found in the heart.

Conclusions: We report here OHCAs of non-cardiac cause directly implicating COVID-19 at various stages of SARS-CoV-2-related DAD. Thus, autopsy remain of interest during this epidemic, both legally and medically to better understand the pathogenic processes of this emerging infectious disease.
\end{abstract}

Keywords: Severe acute respiratory syndrome coronavirus 2 infection (SARS-CoV-2 infection); coronavirus disease 2019 (COVID-19); cardiac arrest; autopsy

Submitted Jul 28, 2021. Accepted for publication Oct 27, 2021.

doi: 10.21037/atm-21-3918

View this article at: https://dx.doi.org/10.21037/atm-21-3918

\section{Introduction}

On January 25, 2020, Europe was hit by the severe acute respiratory syndrome coronavirus 2 (SARS-CoV-2) pandemic which broke out on December 31, 2019 in Asia (1). On September 30, 2021, the World Health Organization coronavirus disease 2019 (COVID-19) situation report counted 4,771,408 deaths, including 1,335,853 in Europe and 114,421 in France (2). A strong association between cumulative incidence of COVID-19 and of out-of-hospital cardiac arrest (OHCA) was previously reported in the Lombardy region of Italy (3). Some autopsy data on deaths within the health system clarified the pathophysiology of this emerging infection $(4,5)$. However, there is little information 
regarding cause of death in subjects who died at home in a context of suspected COVID-19 during lockdown (6).

We here report the first forensic autopsy series of COVID-19-related OHCA.

We present the following article in accordance with the STROBE reporting checklist (available at https://dx.doi. org/10.21037/atm-21-3918) (7).

\section{Methods}

Research was conducted in accordance with the World Medical Association's Declaration of Helsinki (as revised in 2013). This study was approved by our local institutional review board (Comité d'Ethique du CHU de Lyon), approval protocol number $\mathrm{n}^{\circ} 20-42$. This Institutional Review board waived the need for informed consent given the nature of the study. The methodology of this study was consistent with the STROBE statement for observational studies (7).

Between March 19, 2020 and April 21, 2020, all adult patients with COVID-19-related OHCA were autopsied at the Institute of Legal Medicine of the metropolitan area (1.5 million inhabitants) of Lyon (France). Autopsies adhered to Council of Europe Circular No1159 and safe operating procedures (8). RT-PCR assay for SARS-CoV-2 was conducted on endotracheal swabs and pulmonary samples. Standard histology staining (hematoxylin-eosin) was performed on all organs. General unknown drug screening was carried out using gas chromatography/ mass spectrometry and liquid chromatography/diode array detector/mass spectrometry. Concentrations of detected molecules were measured by specific chromatographic techniques. Blood ethanol concentration was measured by gas chromatography/flame ionization detector.

Descriptive data (without missing data) are expressed as mean \pm SD.

\section{Results}

Four Caucasian individuals ( 3 men, 1 women) presenting virosis and laboratory-confirmed COVID-19 were autopsied. Mean age was $56.8 \pm 2.1$ years old. Complete data were obtained for all individuals.

Individual \#1 was a 59-year-old obese woman [body mass index (BMI): $40 \mathrm{~kg} / \mathrm{m}^{2}$ ] with mental deficiency, suffering for 7 days from an undiagnosed respiratory syndrome and a pain in a foot treated with non-steroidal anti-inflammatory drug. She presented a cardiac arrest at home in the presence of her brother (also mentally deficient). Despite the intervention of the mobile emergency care service (MECS), she died during her transport to the hospital. Individual \#2 was a 57 -year-old man (BMI: $29 \mathrm{~kg} / \mathrm{m}^{2}$ ), treated for one year for myeloma. Twenty-four hours after a $4^{\text {th }}$ course of chemotherapy, he presented fever and dyspnea for which he refused to consult his doctor. Four days later, he presented at home a cardiac arrest in the presence of his wife and died during his medicalized transport to the hospital. Individual \#3 was a 57 -year-old man (BMI: $23 \mathrm{~kg} / \mathrm{m}^{2}$ ) with a history of manic-depressive psychosis treated by valproic acid, oxazepam and escitalopram. He presented an undiagnosed respiratory syndrome lasting 4 days that spontaneously resolved a week before his death. He was found dead in his bed by firefighters alerted by his employer, a farewell letter nearby saying he could no longer endure the COVID-19 lockdown. Individual \#4 was a 54-year-old man (BMI: $26 \mathrm{~kg} / \mathrm{m}^{2}$ ) with Crohn's disease treated by alternative medicine. Three days before his death, he presented a respiratory syndrome associating an important cough, diarrhea and asthenia for which he was medically advised to rest. On the $4^{\text {th }}$ day, he was discovered dead in his bed overnight by his wife. The doctor who came did not performed any cardio-pulmonary resuscitation.

Autopsies of individuals \#1, \#2 and \#4 revealed diffusely purplish-red, firm, heavy, congestive edematous lungs (Figure 1A) with parenchymal congestion. Cross-section of the fixed lung showed a typical COVID-19 aspect (Figure 1B). For individual \#4, autopsy also revealed an inferior small cerebellar hemorrhagic lesion (Figure 1C). The heart was free of significant chronic or acute heart lesions and the pulmonary arteries were free of thrombi at the hilum in the 3 individuals. Autopsy of individual \#3 showed vomiting, alcoholic body-odor, organ congestion and airway aspiration.

Histology confirmed diffuse alveolar damage (DAD) with typical alveoli lined with hyaline membranes at different stages of inflammatory reaction: vasculo-exudative phase (individual \#1, Figure 1D), early cellular phase (individual $\# 2$, Figure $1 E$ ) and resorptive/organizing phase (individual \#4, Figure $1 F$ ). Interestingly, foci of atypical pneumocytes showing characteristic viral cytopathogenic effect were disseminated across the DAD lesions. No inflammatory lesions of vessels or endothelial cell alteration were found. Lung tissue from individuals \#1 and \#4 (Figure 1G) showed multiple non-organized thrombi. The cerebellar lesion in individual \#4 was small hemorrhagic infarct, a few days old, with a venous thrombus walled with endothelial cells. Histology of lung tissue from individual \#3 confirmed 

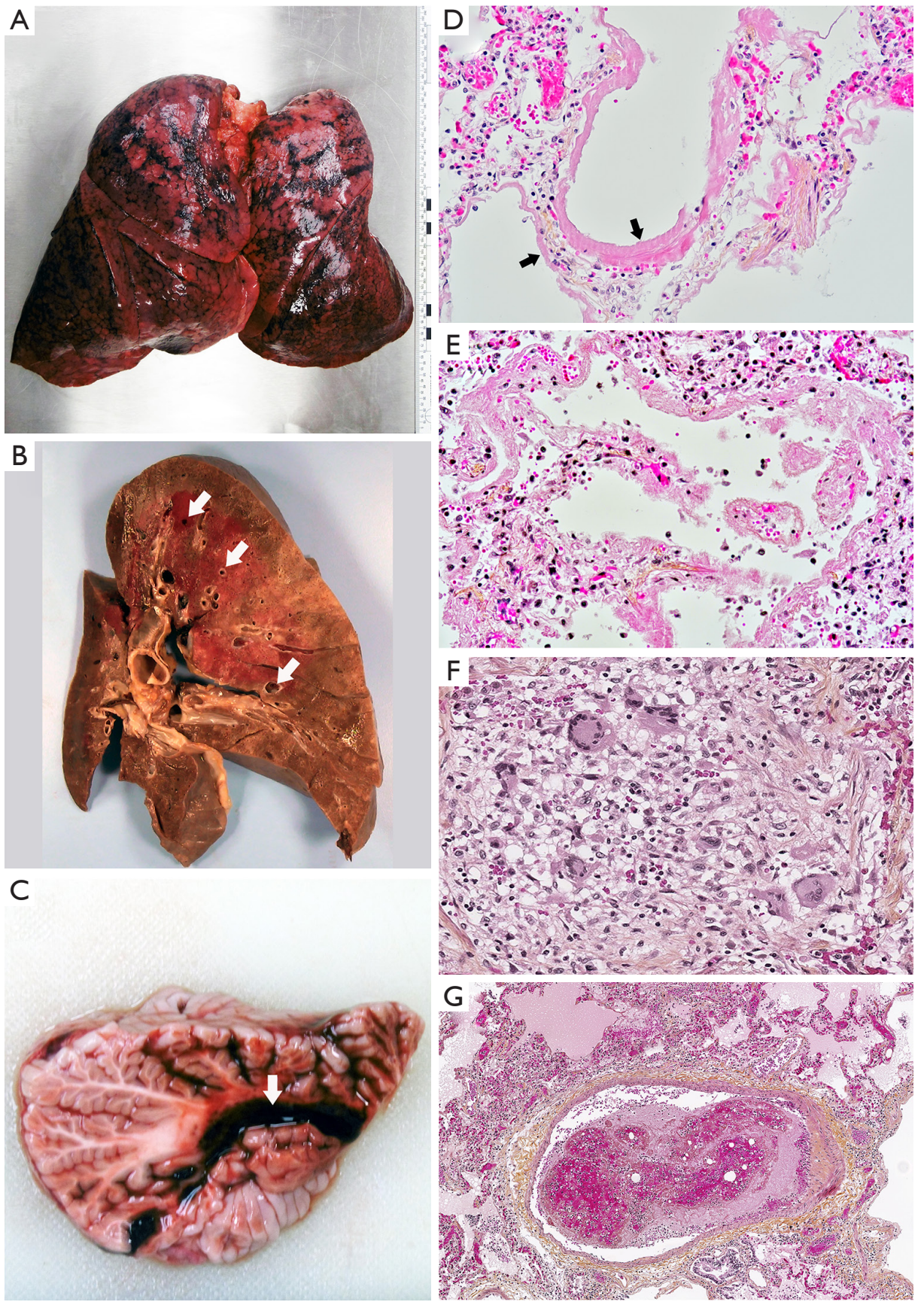

Figure 1 Gross findings and pulmonary microscopy findings in COVID-19-related out-of-hospital cardiac arrest. (A) Diffusely purplishred, firm, heavy lungs from individual \#4. Right lung: 1,110 g (normal: $651 \pm 241 \mathrm{~g}$ ); left lung: $740 \mathrm{~g}$ (normal: $579 \pm 201 \mathrm{~g}$ ). (B) Cross-section of fixed right lung from individual \#1 showing light brown areas, (consolidation), dark brown areas (congestion), and small peripheral thrombi (arrows). (C) Right cerebellar small $(0.8 \mathrm{~cm} \times 2 \mathrm{~cm})$ inferior infarct (arrow) without tonsillar involvement in individual \#4. (D) Vasculoexudative phase of DAD with alveoli lined hyaline membranes (arrows), interstitial edema, congestion and rare lympho-monocytic infiltrate (HE stain, $\times 200$ ) from individual \#1. (E) Early cellular phase of DAD with macrophage, lymphocytic and neutrophilic infiltrates (HE stain, $\times 200$ ) from individual \#2. (F) Resorptive/organizing phase of DAD with light alveolar walls thickening, giant multinucleated cells infiltrate in lumen and bronchiolar metaplasia of alveoli (HE stain, $\times 200$ ) from individual \#4. (G) Non-organized thrombi in lung tissue (HE stain, $\times 100$ ) from individual \#4. DAD, diffuse alveolar damage; COVID-19, coronavirus disease 2019; HE, hematoxylin eosin. 
the diagnosis of airway aspiration. For all individuals, no significant lesions were found in the other organs, including the heart.

No evidence of toxic involvement was found for individuals \#1, \#2 or \#4. For individual \#3, blood-alcohol was $5.04 \mathrm{~g} / \mathrm{L}$, and valproic acid blood concentration $27 \mu \mathrm{g} / \mathrm{mL}$ (therapeutic range, $40-100 \mu \mathrm{g} / \mathrm{mL}$ ).

In all, autopsy reported natural death by acute respiratory failure implicating SARS-CoV-2 for individuals \#1, \#2 and \#4, and violent death due to suicidal acute alcohol intoxication for individual \#3.

\section{Discussion}

Only forensic autopsy determines both cause and circumstances of death. We report here three OHCAs of non-cardiac cause directly implicating COVID-19 and one suicide related to the lockdown.

Main lung histopathological findings (i.e., DAD with alveoli lined hyaline membranes, small peripheral thrombi, lymphocytic and neutrophilic infiltrates) in these cases of OHCA were very similar to those observed in other patients who died of COVID-19 pneumonia (5). Interestingly, sudden death can occur at various stages of SARS-CoV2 -related DAD. Moreover, unlike what was reported in a series of hospital autopsies (4), the cause of death appears mainly due to lung damage without any major additional mechanism in particular cardiovascular (e.g., pulmonary embolism).

As previously reported since the beginning of the pandemic (9), in the absence of any other obvious cause, the sudden deaths of individuals \#1, \#2 and \#4 were attributed to hypoxic OHCA secondary to acute respiratory failure complicating SARS-CoV-2-induced bilateral severe pneumonia. According to the Utstein style (10), asphyxia is well admitted as one of the main causes of sudden death by cardiac arrest. This is particularly true for nonshockable cardiac arrest with asphyxia or respiratory failure accounting for $23 \%$ to $56 \%$ of the causes of sudden death in three large cohorts of cardiac arrest with nonshockable rhythm (11-13). This point was also highlighted in the recent report from the Swedish Registry for Cardiopulmonary Resuscitation for COVID-19 positive patients with OHCA during the first wave of the pandemic (14).

In agreement with a previous commentary (15), this report also emphasizes that autopsy, with appropriate indications and technical and safety protocols (8), is of obvious interest during this epidemic, both legally and medically. Finally, it seems important to consider that autopsy can dramatically help in the understanding of the pathogenic processes of this emerging infectious disease.

\section{Acknowledgments}

Funding: None.

\section{Footnote}

Reporting Checklist: The authors have completed the STROBE reporting checklist. Available at https://dx.doi. org/10.21037/atm-21-3918

Data Sharing Statement: Available at https://dx.doi. org/10.21037/atm-21-3918

Conflicts of Interest: All authors have completed the ICMJE uniform disclosure form (available at https://dx.doi. org/10.21037/atm-21-3918). The authors have no conflict of interest to declare.

Ethical Statement: The authors are accountable for all aspects of the work in ensuring that questions related to the accuracy or integrity of any part of the work are appropriately investigated and resolved. The study was conducted in accordance with the Declaration of Helsinki (as revised in 2013). The study was approved by the institutional ethics committee of the CHU de Lyon, approval protocol number $\mathrm{n}^{\circ} 20-42$, with a waiver for written inform consent because of the nature of the study.

Open Access Statement: This is an Open Access article distributed in accordance with the Creative Commons Attribution-NonCommercial-NoDerivs 4.0 International License (CC BY-NC-ND 4.0), which permits the noncommercial replication and distribution of the article with the strict proviso that no changes or edits are made and the original work is properly cited (including links to both the formal publication through the relevant DOI and the license). See: https://creativecommons.org/licenses/by-nc-nd/4.0/.

\section{References}

1. Dong E, Du H, Gardner L. An interactive web-based dashboard to track COVID-19 in real time. Lancet Infect Dis 2020;20:533-4.

2. World Health Organization. WHO Coronavirus disease 
(COVID-2019) Dashboard. Available online: https:// covid19.who.int. Date last accessed: September 30, 2021.

3. Baldi E, Sechi GM, Mare C, et al. Out-of-Hospital Cardiac Arrest during the Covid-19 Outbreak in Italy. N Engl J Med 2020;383:496-8.

4. Barton LM, Duval EJ, Stroberg E, et al. COVID-19 Autopsies, Oklahoma, USA. Am J Clin Pathol 2020;153:725-33.

5. Menter T, Haslbauer JD, Nienhold R, et al. Postmortem examination of COVID-19 patients reveals diffuse alveolar damage with severe capillary congestion and variegated findings in lungs and other organs suggesting vascular dysfunction. Histopathology 2020;77:198-209.

6. Aguiar D, Lobrinus JA, Schibler M, et al. Inside the lungs of COVID-19 disease. Int J Legal Med 2020;134:1271-4.

7. von Elm E, Altman DG, Egger M, et al. The Strengthening the Reporting of Observational Studies in Epidemiology (STROBE) statement: guidelines for reporting observational studies. PLoS Med 2007;4:e296.

8. Hanley B, Lucas SB, Youd E, et al. Autopsy in suspected COVID-19 cases. J Clin Pathol 2020;73:239-42.

9. Chen N, Zhou M, Dong X, et al. Epidemiological and clinical characteristics of 99 cases of 2019 novel coronavirus pneumonia in Wuhan, China: a descriptive

Cite this article as: Fanton L, Nahmani I, Epain M, Advenier AS, Cour M, Meyronet D, Argaud L. Forensic autopsyconfirmed COVID-19-induced out-of-hospital cardiac arrest. Ann Transl Med 2021;9(23):1715. doi: 10.21037/atm-21-3918 study. Lancet 2020;395:507-13.

10. Langhelle A, Nolan J, Herlitz J, et al. Recommended guidelines for reviewing, reporting, and conducting research on post-resuscitation care: the Utstein style. Resuscitation 2005;66:271-83.

11. Cour M, Bresson D, Hernu R, et al. SOFA score to assess the severity of the post-cardiac arrest syndrome. Resuscitation 2016;102:110-5.

12. Argaud L, Cour M, Dubien PY, et al. Effect of Cyclosporine in Nonshockable Out-of-Hospital Cardiac Arrest: The CYRUS Randomized Clinical Trial. JAMA Cardiol 2016;1:557-65.

13. Lascarrou JB, Merdji H, Le Gouge A, et al. Targeted Temperature Management for Cardiac Arrest with Nonshockable Rhythm. N Engl J Med 2019;381:2327-37.

14. Sultanian P, Lundgren P, Strömsöe A, et al. Cardiac arrest in COVID-19: characteristics and outcomes of in- and out-of-hospital cardiac arrest. A report from the Swedish Registry for Cardiopulmonary Resuscitation. Eur Heart J 2021;42:1094-106.

15. Sapino A, Facchetti F, Bonoldi E, et al. The autopsy debate during the COVID-19 emergency: the Italian experience. Virchows Arch 2020;476:821-3. 